\title{
Diseños Globales e Historias Locales: Origen y Desarrollo de una Propuesta Educativa en un Museo Interactivo de Ciencias y Tecnologías en el Sur
}

Projetos Globais e Histórias Locais: Origem e Desenvolvimento de Uma Proposta Educacional em um Museu Interativo de Ciência e Tecnologia no Sul

Local Histories and Global Designs: Creation and Development of an Educational Model in an Interactive Science and Technology Museum in the South

Manuel Franco-Avellaneda, Diego Corrales-Caro

Palavras clave Resumen El artículo presenta las condiciones de producción, Educación no- desarrollo y consolidación de una propuesta educativa al interior de un formal; museo interactivo de ciencia y tecnología en Bogotá, Colombia. Esta Paulo Freire; propuesta se fundamenta en el referencial freireano y en los estudios clubes de ciencia y sociales de la ciencia y la tecnología, en consecuencia, reconoce que tecnología; los centros de ciencia son escenarios de encuentro, lugares en los que museos interactivos de ciencia y tecnología; educación científica

y tecnológica. suceden dinámicas de diálogo, negociación, comprensión y aumento de conciencia de situaciones problema. En ese sentido, el presente trabajo aborda, en primera instancia, la genealogía de la propuesta pedagógica, para luego presentar su estructura didáctica y sus adecuaciones en medio de la contingencia del COVID-19. De manera particular se detiene en un programa implementado en medio de esta pandemia: Chicas STEAM. En el cierre, el artículo propone ciertas cuestiones sobre los cambios educativos y la vigencia del pensamiento freireano en el contexto de esta contingencia. 
Palavras-chave Resumo $O$ artigo apresenta as condições de produção, Educação não desenvolvimento e consolidação de uma proposta educativa em um formal; museu interativo de ciência e tecnologia em Bogotá, Colômbia. Tal Paulo Freire; proposta fundamenta-se no referencial freireano e nos estudos sociais clubes de ciência e da ciência e tecnologia e, por conseguinte, reconhece que os museus de tecnologia; ciência são lugares de encontro, espaços onde se acontecem dinâmicas museus interativos de diálogo, negociação, compreensão e aumento de consciência das de ciência e situações problema. Nesse sentido, este artigo aborda inicialmente tecnologia; a genealogia da proposta pedagógica e desenvolve a sua estrutura educação em didática e suas adaptações em meio da contingência do COVID-19. ciência e tecnologia. Particularmente apresenta um programa implementado em meio da pandemia: "Chicas STEAM". Para encerrar, o artigo propõe algumas questões sobre as mudanças educacionais e a validade do pensamento freireano no contexto desta contingência.

Keywords Abstract This paper presents the conditions of production, Non-formal development, and consolidation of an educational model in an education; interactive science and technology museum in Bogotá, Colombia. Paulo Freire; This model is based on Freire's theory in dialogue with Social science and Studies of Science and Technology. In this sense, we understand technology clubs; that Science Centers are gathering places where the dynamics of interactive science dialogue, negotiation, comprehension and awareness of problem and technology situations occur. Thus, this paper addresses the genealogy of this museums; teaching proposal and its structure and adaptations in the context science and of the COVID-19 pandemics, focusing on the program called Chicas technology STEAM. Finally, we raise some questions about educational changes education. and the validity of Freire's thought in post-COVID times. 


\section{Introducción}

La propuesta sobre la cual se originaron los museos y centros interactivos de ciencia plantea ofrecer una experiencia directa con los fenómenos naturales, físicos y tecnológicos, bajo el supuesto de que esto aumentará en los visitantes la confianza y el desarrollo de habilidades para comprender el mundo que los rodea. En este sentido, se diseñan exposiciones interactivas con la intención de que sus visitantes puedan, entre otras expectativas conducir la actividad, reunir evidencias, seleccionar opciones, sacar conclusiones, modificar situaciones dependiendo de las propuestas hechas (Allen \& Gutwill, 2004).

Desde sus inicios, estos museos, centraron sus acciones en comunicar y formar en y sobre ciencias y tecnologías, porque se considera que el aprendizaje de estos conocimientos es necesario para la ciudadanía (Bradburne, 1998). Estos escenarios conocidos en algunos contextos como science centers (Centros de ciencia) están más dedicados a propiciar experiencias para sus públicos que a exhibir y mantener colecciones de objetos. Esta propuesta comenzó, entre otras instituciones, en el Exploratorium de San Francisco-EUA y el Ontario Science Center en Toronto-Canadá, que abrieron sus puertas a finales de la década de los 60 .

En América Latina y específicamente en Colombia la historia de los museos interactivos se ha configurado en una interacción y resistencia entre diseños globales e historias locales. Esto porque además de los referentes de los países centrales, existen elementos a considerar en los tejidos locales. Por ejemplo, investigaciones realizadas en varios países de la región muestran que los museos aún están a medio camino para alcanzar el protagonismo que les permita contribuir significativamente en la democratización del conocimiento científico (Castellanos et al., 2009; Coimbra et al., 2012; Falcão et al., 2010). Así, no han logrado incluir, interesar ni llegar a la mayoría de la población por una variedad de factores como el costo de la entrada cuando esta no es libre, falta de interés de los públicos, desconocimiento, poca o ninguna disponibilidad en regiones aisladas.

En este sentido, la deslocalización se ha convertido en una impronta clave para superar barreras de disponibilidad y acceso. Así, Espaço Ciência Viva (EVC) en Rio de Janeiro y el Museo de la Ciencia y el Juego (MCJ) en Bogotá, pueden caracterizarse por la consigna del ECV "o cientista tem que ir aonde o povo está", que ejemplifica actividades realizadas en espacios públicos, barrios de baja renta, y ciudades con poca o ninguna infraestructura cultural para la apropiación social del conocimiento científico y tecnológico (Franco-Avellaneda, 2013b). Por su parte el MCJ busca, con el programa Maletas del Museo, llegar a lugares aislados sociocultural, económica y geográficamente, esto por medio de exposiciones enmaletadas de bajo costo.

La intención de deslocalizar el museo es una idea presente desde la declaración de la Mesa de Santiago en 1972 (Fernández-Guido, 1973). Luego, con el surgimiento del Movimiento Internacional por una Nueva Museografía (MINOM), en la década de los 80, en el campo de museos se fortaleció el interés por lo rural, la desigualdad de 
acceso a la infraestructura cultural, y la conciencia de que los museos son parte de una comunidad, a la cual sirven, deben escuchar y tomar en cuenta (Arroyo et al., 2011).

Tal vez por el desconocimiento de estos planteamientos locales, para no atribuir decisiones deliberadas, a partir de la década de los 90 se expandió en Latinoamérica el modelo de infraestructura que caracterizó el boom de los science center (Beetlestone et al., 1998), el cual se sustentó en grandes construcciones, teatros de formato gigante, uso de tecnologías digitales, robótica, realidad virtual, etc. Este modelo global animado por una racionalidad económica más que educativa, evidenció en medio de la actual pandemia del COVID-19 grandes dificultades de sostenibilidad, corroborando los planteamientos de más de dos décadas realizados por Bradburne (1998).

Bradburne (1998) propone dos argumentos, de un lado, usando la metáfora de la extinción de los dinosaurios, muestra que la gran necesidad de recursos para el funcionamiento de estos escenarios les hace muy frágiles a los cambios repentinos de condiciones socioculturales, políticas y económicas. De otro lado, los considera elefantes blancos, por sus altas inversiones en la construcción, operación y mantenimiento, las cuales se justificaron en parte por la diversión, que ya no puede competir con la industria del entretenimiento pues esta logró introducir una serie de tecnologías en el hogar que inicialmente hacían parte del atractivo de los science center - controles activos, juegos en línea, robótica, etc-.

Otro de los aspectos, por la que son fuertemente criticados sostiene que son "lugares sin memoria" (Bonatto, 2012), pues su noción de interactividad parece relacionada con una capacidad para la acción asociada al reflejo, más que a la reflexión, y además la mayoría de sus contenidos están disociados de sus relaciones históricosociales. Así las cosas, la ruptura de estos nuevos museos con respecto a los tradicionales, caracterizados por colecciones, parece significar el paso de una memoria para preservar a una no-memoria, por tanto, existe una fuerte necesidad de rescatar una memoria para movilizar procesos de problematización-decodificación del presente atravesado por lo científico-tecnológico.

Después de casi cuatro décadas del surgimiento de estos escenarios en América Latina, persisten al menos tres puntos en discusión, que marcan los debates y posicionamientos educativos de estos escenarios:

La no neutralidad de las exposiciones. La proliferación delos museos interactivos de ciencia y tecnología estuvo animada en los años 90 y 2000, por la réplica y compra de exposiciones desarrolladas en el Exploratorium, en especial por la colección de libros Exploratorium Cookbook. Son estos, libros que proporcionaban planos de detalle y recetas para la construcción de artefactos, que permitieron a muchos escenarios tener la confianza y el conocimiento para desarrollar sus propias exposiciones interactivas. Con esto, muchos espacios replicaron y compraron artefactos sin reconocer que estas exposiciones tienen agencia y embarcan ciertas ideas en su diseño y estructura (FrancoAvellaneda, 2013c). 
En definitiva, la buena intención del Exploratorium de ofrecer recetas para construir exposiciones, se reconfiguró en los años 90 y 2000 en una industria global del edu-entretenimiento que empujó a muchos gobiernos a construir un science center en sus ciudades como símbolo de modernidad. Sin muchas oposiciones, en América Latina se usaron cantidades significativas de recursos sin importar qué ideas se maternizaban, qué ciencia se privilegiaba y cuáles eran los supuestos de uso que concibieron los diseñadores.

Ciencia en acción, más que los productos de la ciencia. La configuración de museos interactivos en la lógica de copiar y comprar sus exposiciones terminó privilegiando la promoción de productos de la ciencia y en algunos casos sirviendo de plataforma de mercadeo de empresas. Esto último es evidente en museos icónicos de Latinoamérica como Maloka en Bogotá ${ }^{1}$ y Papalote Museo del Niño en Ciudad de México (Franco-Avellaneda, 2013a). Opuesto a esta situación, trabajos y proyectos recientes defienden que el papel del museo está dirigido a permitir la discusión, negociación e intercambio de ciencias y tecnologías en construcción (Franco-Avellaneda \& Arboleda, 2014), es decir, lo educativo permitiría la reflexividad y el aumento de conciencia de los actores implicados en una situación problema, intereses y circunstancias específicas (Freire, 2005), esto sería posible gracias a que el museo presenta y aborda las ciencias y las tecnologías en acción. Es decir, deja ver el proceso de configuración, controversias, métodos y valores de acuerdo con la idea propuesta por Latour (1987).

Más que entretener, promover ciudadanías. El boom de los science center además de posicionar un mercado de exposiciones, evidente en los encuentros promovidos por la Association of Science and Technology Centers (ASTC), promocionó la idea de educación-entretenimiento (edu-entretenimiento). Según Resnick (2004) esta idea distorsiona la comprensión de educación, al suponer que se trata de una amarga medicina que necesita endulzarse con entretenimiento para que sea digerible. Así las cosas, parece persistir una tensión entre edu-entretenimiento, playful learning y espacios maker.

Por un lado, se entienden como espacios de aprendizaje activo en la medida que involucran y animan a quienes participan a desarrollar, diseñar y crear su propio contenido. De otro lado, con el surgimiento de nuevos escenarios que se distinguen por su impacto colectivo y la colaboración entre personas que trabajan para materializar proyectos para un bien común —espacios hacker, minga labs, co-laboratorios, cafés de reparación- (Charter, 2018). Estos recientes espacios se encuentran dentro de una acción política, desde ellos se identifica a las ciencias y tecnologías como no neutrales, por lo cual existirían alternativas científico-técnicas para elegir y deliberar en presencia de diversos actores sociales como comunidades de software libre, emprendedores, jóvenes estudiantes, etc. (Braybrooke \& Smith, 2018). Tales alternativas las identifican como la base material que determina la viabilidad de ciertos modelos socioeconómicos y políticos, así como la imposibilidad de otros. En consecuencia, estos son escenarios de participación de un componente mayor que llamaríamos democracia-sociotécnica (Franco-Avellaneda, 2016; Thomas, 2009).

1 Maloka es uno de los museos interactivos más grandes de Sudamérica. Más información ver: https://maloka.org/ 
El anterior panorama presenta el contexto de origen de una propuesta educativa que surge al interior de un museo interactivo de ciencia y tecnología llamado Maloka, en los años 2000, la cual se fortalece en medio de la contingencia del COVID-19, se fundamenta en los planteamientos freireanos y en los estudios sociales de la ciencia y la tecnología y, en consecuencia reconoce que los centros de ciencia son escenarios de encuentro, lugares en los que suceden las dinámicas de diálogo, negociación, comprensión y aumento de conciencia de situaciones problema (Chavot \& Masseran, 2010; Freire, 1977). Su papel social se configura en la aparente frontera que separa dos mundos definidos por sus valores culturales, la ciencia y la sociedad, de esto dependería el éxito social de los escenarios autodenominados como de apropiación social del conocimiento (Franco-Avellaneda, 2016).

En ese sentido, el presente artículo aborda en primera instancia la genealogía de una la propuesta educativa en un escenario de educación no-formal, de la mano de un proceso de investigación-acción. Después desarrolla la estructura pedagógica y sus adecuaciones en medio de la contingencia del COVID-19. Luego, presenta un programa implementado en medio de la pandemia: Chicas STEAM. En el cierre, el artículo propone ciertas cuestiones sobre los cambios educativos y la vigencia del referencial freireano.

\section{Genealogía de una propuesta educativa en un museo de ciencia: la situación problema}

La propuesta de cuatro momentos pedagógicos, que se aborda en el presente artículo, nace en un momento de gran reconocimiento y protagonismo de Maloka. Esto fue evidente, en la encuesta de percepción pública de la ciencia que se realizó en Colombia en el 2005 en la que Maloka aparece como el lugar más reconocido por los y las docentes como escenario propicio para el aprendizaje lúdico. La encuesta también muestra que Maloka es vista por docentes de educación básica, media y por la empresa privada, como la institución que lideraba en Colombia la generación de conocimiento científico y tecnológico, ubicándola por encima de universidades e institutos de investigación del país ${ }^{2}$. Esta circunstancia era paradójica, como lo mencionó Jesús Martín-Barbero, porque el público "no tiene nada claro dónde se hace la investigación pues confunde la generación de conocimiento con la promoción y divulgación de la actividad científica” (2005, p. 45).

Esta percepción parte de una suerte de delegación proveniente de múltiples actores sociales como la empresa privada, educadoras, educares e incluso Secretarías de Educación, que reconocen un papel preponderante de estos escenarios como espacios para el aprendizaje de las ciencias y las tecnologías. Ejemplo de ello es lo que sucede con la política científica en su momento, que atribuye a escenarios como Maloka tareas de motivar e interesar en ciencias y tecnologías (Colciencias, 2005). Así las cosas, el contexto político en el que se posiciona Maloka, y en general los museos interactivos

2 La encuesta identificó a Maloka por encima de Universidades como la Universidad del Valle, la Universidad de los Andes, la Pontificia Universidad Javeriana, la UIS Universidad Industrial de Santander e institutos de investigación como CORPOICA, CENICAFÉ, Instituto Humboldt, entre otros. 
más emblemáticos de Colombia, llevó a que la popularización y divulgación de ciencias y tecnologías que tenían lugar en estos lugares fuera poca discutida. En este sentido, al tiempo que se abogaba por el derecho que tiene la ciudadanía a educarse en ciencias, parecía también que se promoviera la existencia y acceso a estos escenarios como un derecho, en tanto que se legitimaban como una de las maneras para acercarse a entender el mundo en el que estamos inmersos y que operarían como complemento y en algunos casos como suplencia de la labor de la escuela (Costantin, 2001).

El rol preponderante y la importancia que alcanzaron en el contexto colombiano los museos interactivos en la década del 2000 estuvo basado en la seducción y en la fascinación muchas veces descontextualizada, lo que de alguna manera contribuía a reforzar el determinismo tecnocientífico (Thomas, 2008) y la promoción de la ciencia y la tecnología desde el consumo, todo lo anterior ayudando a reforzar la posición histórica de Colombia como un país en vía de desarrollo. En este sentido, es posible afirmar que los museos interactivos también serían responsables de las visiones de ciencia y tecnología que se construyen en el escenario social colombiano, así como de los reduccionismos y malentendidos presentes en los ciudadanos sobre estos temas.

Ahora bien, la propuesta de cuatro momentos pedagógicos inicial no aprovechó los desarrollos de los años 80 y 90, en Brasil, orientados a fortalecer la educación en ciencias en la perspectiva educacional freireana (Delizoicov, 1982, 2008; Delizoicov \& Angotti, 1990; Delizoicov et al., 2007; Menezes, 1980), que tienen como fundamento las categorías dialogicidad, problematización y concientización, articuladas a su vez con temas generadores. En los trabajos recientes es evidente el abordaje temático freireano, pues existe una preocupación permanente por tener en cuenta el contexto de generación del conocimiento, producido socio-históricamente y de manera provisional - no neutralidad del sujeto y del objeto de conocimiento-, asimismo el contexto de apropiación de ese conocimiento en el proceso educativo.

De igual forma, se fundamenta en las aproximaciones entre las perspectivas CTS (ciencia, tecnología y sociedad) y la propuesta educativa freireana (Auler \& Delizoicov, 2006; Delizoicov \& Auler, 2011; Franco-Avellaneda, 2013a; Franco-Avellaneda \& VonLinsingen, 2011). En ese sentido se argumenta que una lectura crítica de diversos contextos implica necesariamente una comprensión crítica de las interacciones entre ciencia, tecnología y sociedad. Por eso, se considera fundamental la problematización de construcciones poco consistentes presentes en las actividades científico-tecnológicas derivadas de supuestos de neutralidad de las ciencias y las tecnologías - superioridad del modelo de decisiones tecnocráticas, perspectiva salvacionista o redentora atribuida a las ciencias y las tecnologías, y el determinismo tecnológico-.

En consecuencia, la propuesta de cuatro momentos pedagógicos se constituye en una herramienta significativa de resistencia frente a visiones de neutralidad del conocimiento científico y tecnológico, que como hemos señalado, con frecuencia se promueven desde los museos interactivos de ciencia y tecnología. El caldo de cultivo de esta iniciativa sucedió en los clubes de ciencia para niños, niñas, adolescentes y jóvenes que tenían lugar los sábados en Maloka, en los primeros años de la década del 2000. 
A continuación, se muestra la forma en que se abordó la situación problema presentada, desde el espacio educativo de los clubes a partir de entenderlos como un escenario de reflexión frente al papel del centro interactivo y posicionamiento político frente a la lógica de mercado que con frecuencia animó sus acciones (Daza et al., 2006).

\section{Apuntes metodológicos para superar la situación problema}

Los clubes de ciencia y tecnología que dieron origen a la propuesta de cuatro momentos pedagógicos convocaban niños, niñas, adolescentes y jóvenes de 4 a 15 años de edad, que se reunían en sesiones de tres horas, una vez por semana, en periodos semestrales. Las temáticas abordadas en los clubes eran astronomía, biología, robótica, química, energía, aire y vuelo.

Tales temáticas permitían una relación con la sociedad que era posible desde la propuesta educativa de los clubes, en dos sentidos. Por un lado, estas daban lugar a un abordaje disciplinar que reflexionaba sobre el contexto, situando una problemática que acerca a los y las participantes a preguntas tecnocientíficas con frecuencia desconocidas en su entorno cercano. Por otro lado, las temáticas propuestas también potenciaban la reflexión social de quienes orientan las sesiones de los clubes. Esta labor era realizada por estudiantes de carreras afines con estas áreas del conocimiento; la participación de jóvenes estudiantes de universidad, que inicialmente sólo buscaba suplir una necesidad de intermediación disciplinar — contar con personas mediadoras que orientaran a niños y niñas-, poco a poco se convirtió en un ejercicio de reflexividad sobre sus propios conocimientos disciplinares que complementaba la formación profesional que recibían en la universidad.

Estudiantes de últimos semestres de carreras como ingeniería, física, licenciatura electrónica, entre otras, al enfrentarse al reto de comunicar y transmitir conceptos relacionados con la disciplina que estudiaban, configuraban una experiencia de diálogo con niños y niñas, al igual que con otros actores, como las familias de los participantes y los científicos que visitaban las sesiones de los clubes. Esta circunstancia empezó a orientar la dinámica del club, en tanto que puso en interacción el aprendizaje que reciben niños y niñas en los campos científicos y tecnológicos de los clubes, con los cuestionamientos sobre las áreas del saber que estudiaban los mediadores e incluso sobre su propio futuro profesional. De este modo, los conocimientos que se trabajaban durante las sesiones reclamaban una puesta en un contexto social, que daba la oportunidad a los y las mediadoras de descubrir, ayudadas por los niños y niñas, la pertinencia de lo que aprendían, el para qué de una solución científica o tecnológica y el cómo desarrollarla teniendo en cuenta la decodificación del contexto (Freire, 2005).

En esta apuesta por la interlocución de saberes, por una parte, los niños y las niñas que tenían un saber configurado a partir de la experiencia de habitar en un mundo tecnocientífico, pues al ser usuarios tecnológicos estaban en posibilidad de hablar desde su experiencia, no participaban del club para ser usuarios cultos, sino para ser diseñadores-desarrolladores, usuarios y usuarias críticas de las ciencias y 
tecnologías (Dussel, 1995). De otra parte, estaban las y los mediadores que contaban con un saber disciplinar adquirido en su formación universitaria, el cual se enriquecía cuando intentaban orientar las sesiones de los clubes y estaban obligados a reconocer el contexto social de los y las participantes. La interacción dialógica que estaba a la base de la propuesta educativa de los clubes era posible gracias a que los proyectos que se realizaban en las sesiones eran propuestos y construidos por los niños y las niñas, pero se materializaban gracias a la discusión con las y los mediadores.

La propuesta de cuatro momentos pedagógicos, en un comienzo se conoció con el nombre de Motivación para la creación, fue desarrollada por el equipo de Maloka a partir de un proceso de investigación acción sobre las dinámicas que se estaban implementando en los clubes. Inicialmente la propuesta se desarrollaba en tres momentos pedagógicos: motivación, creación y reflexión, estos fueron pensados desde la idea del diálogo de saberes y desde una lectura crítica de lo científico-tecnológico en relación con el mercado y su aplicación apropiada al contexto. Estos momentos se organizaron con instrumentos de seguimiento, para que mediadores y mediadoras los tuvieran en cuenta a la hora de planear las sesiones y los aplicarán en las actividades con los participantes.

Quienes hacían la mediación debían iniciar la sesión acercándose al saber tecnocientífico de los y las participantes, particularmente desde la exploración de sus referentes cotidianos - motivación-, para luego introducir actividades que enriquecieran estos referentes a través de la resolución de problemas prácticos, el diseño y la manipulación de materiales, así como el conocimiento de fenómenos o principios - creación-, y que invitaran a niños y niñas a repensar su cotidianidad relacionando lo que sabían al inicio de la sesión y lo que sabían luego de haber diseñado e intentado resolver un problema de manera creativa - reflexión- (Pérez-Bustos \& FrancoAvellaneda, 2005).

El proceso de investigación acción, se desplegó durante los años 2005 y 2006, usando entrevistas semiestructuradas a las y los mediadores que buscaban dar cuenta de cómo se estaba apropiando la estructura inicialmente definida. Junto con esto se implementaron instrumentos de sistematización que funcionaban como guías de sistematización para que quienes hacían la mediación documentaran cómo había sido cada sesión (se realizaban al final de la sesión). Y finalmente, los diarios de campo de observación externa realizados por el equipo de esa época de investigación y desarrollo de Maloka.

Esta indagación permitió evidenciar que el trabajo con los niños y las niñas estaba planteando una relación distinta de los y las jóvenes universitarias con su ejercicio profesional, como se señalaba anteriormente; sin embargo, también permitió ver que estas personas a cargo de la mediación no hacían una lectura crítica sobre el papel de las ciencias y tecnologías como estaba previsto, sino que con frecuencia reproducían una lógica de consumo en relación con estas. A continuación, se presentan los principales hallazgos y los ajustes propuestos en diálogo con la realidad actual en el marco de la pandemia mundial de COVID-19. 


\section{La estructura educativa: de motivar para crear a explorar para vincular el mundo}

El desarrollo de la propuesta, aunque tuvo como punto de partida el quehacer de las y los mediadores, no se pensó como un proceso enteramente participativo, de modo que las reflexiones que enriquecieron práctica y teóricamente la propuesta les llegaron terminadas, discutidas e incluso validadas en contextos como el Servicio Nacional de Aprendizaje (SENA), la Fundación Unión Fenosa y el Ministerio de Educación Nacional ${ }^{3}$. La ausencia de las y los mediadores en el ejercicio de definir las orientaciones pedagógicas de los clubes fue compensada con la declaración de lineamientos y su subsiguiente aplicación en el proceso de planear las sesiones con los niños y las niñas. Para ese fin, se generaron listas de chequeo que permitieran orientar la elaboración de las guías en las que estuvieran explicados los tres momentos de la propuesta, para ello se diseñaron instrumentos de seguimiento desde la estructura metodológica para orientar la reflexión de las y los mediadores — guías de sistematización - y se realizaron observaciones externas para hacer seguimiento al papel que desarrollaban en la mediación.

Este proceso de seguimiento no derivó en un ejercicio reflexivo sobre la propuesta. Lo que trajo como resultado que los imaginarios sobre lo que significa cada momento se convirtieran en procesos mecanizados, y se vieran como cosas que hay que hacer, pero sobre las que no había claridad o consciencia de su importancia. Ejemplo de ello fue la recurrente omisión del cierre en las sesiones en donde se reflexionaba con los niños y las niñas sobre la experiencia vivida y se recogían los referentes iniciales a la luz del ejercicio creativo. A manera de ejemplo, se presentan a continuación algunas de las respuestas dadas en ese momento por las y los mediadores, a la pregunta: Al final de la sesión es importante que relaciones el reto o la actividad central con lo que pasó en la actividad motivadora. Cuéntanos cuál fue tu papel para lograr establecer esta relación con los participantes.

- [...] fue terrible esta parte, los muchachos engomados cortando y armando su ranita, y llegamos nosotros a decirles que pararan para terminar la guía, lograr ordenar el salón fue casi imposible, los pelados nos detestaron cuando les quitamos las herramientas para lograr que nos prestaran atención para hacer el cierre (Sistematización de la sesión de 3 de agosto de 2005).

- No se relacionaron las preguntas iniciales con la actividad central. No se alcanzó a realizar el cierre (Sistematización de la sesión de 6 de septiembre 2005).

- [...] Ninguno, desaproveché por completo esta sesión, al final se intentó con muy poco éxito hacer un cierre de algo que nunca se abrió... (Respuesta de la sesión marzo 4 de 2006).

3 La propuesta fue utilizada para apoyar el desarrollo de proyectos encaminados a diseñar estrategias de mejoramiento a las prácticas de aula en el SENA, para orientar la formación y el acompañamiento a distancia de mediadores de clubes de Energía en Barranquilla y fue presentada públicamente en un taller diseñado para el Foro Nacional de Competencias Científicas y Tecnológicas en 2005. 
Este tipo de respuestas se refuerzan con el aparente aburrimiento de las y los niños en la fase inicial de exploración de referentes, que surge como consecuencia de la pasividad con la que las y los mediadores asumían este primer momento.

- Los y las mediadoras estuvieron muy pegadas a la guía ... leen las preguntas y si las respuestas de los y las niñas están bien, entonces bien y si están mal entran a explicar. Se están centrando en explicar términos, pero no interactúan con niñas y niños quienes no hacen preguntas, no se aprovecha más el momento, no se conversa sobre los comentarios, se pasa de una pregunta a otra y de una actividad a otra de manera desconectada (Diario de campo, observación externa, octubre de 2005).

La falta de claridad por parte de las y los mediadores sobre la importancia de estos dos momentos de la actividad, apertura y cierre, sumado a la insistente atención al momento de creación, refuerza una idea muy frecuente en el escenario universitario donde el hacer sobrepasa e incluso desconoce al reflexionar. Este fenómeno, por sí mismo, justifica la existencia de un espacio formal de discusión con el equipo de mediación y un trabajo de seguimiento permanente a su rol en la planeación, ejecución y evaluación de las actividades.

Además de la poca reflexividad sobre los momentos de la propuesta, como resultado del proceso de investigación acción, se identificó que los clubes con frecuencia reproducían un sentido de neutralidad de lo científico-tecnológico. En este sentido, tanto quienes hacían la mediación, como niños y niñas se encontraban al mismo nivel en relación con la mirada ingenua sobre lo científico-tecnológico, unos con más conocimientos sobre cómo funcionan las cosas - principios disciplinares-, pero ambos con la misma intención de crear artefactos y no de reflexionar sobre el contexto como catalizador del proceso creativo. A continuación, comenta uno de los mediadores:

- [...] Lo importante de los clubes es que estamos haciendo tecnología, estamos con los niños y niñas desarrollando procesos tecnológicos ... desarrollando la creatividad ... ellos tienen muchas ideas pues no tienen tantos referentes como uno, esas ideas me ayudan a mí a ser creativo... (Hombre de 22 años. Estudiante de ingeniería mecatrónica, tercer semestre Universidad Nacional de Colombia).

En términos concretos esta posición se centraba en una idea de tecnología que puede arraigar un sistema de producción capitalista que concibe el consumo como un acto de colección (Sarlo, 2001, p. 15) no como un ejercicio de satisfacción de necesidades, situación que ha llevado a que los dispositivos que se creaban en los clubes tuvieran un alto contenido de entretenimiento y fueran vistos incluso como juguetes.

En estas condiciones, en el año 2020, se retoma la propuesta metodológica Motivación para la creación y se la arriesga una vez más a sus propias contradicciones. Es decir, se le somete a un ejercicio deconstructivo de sus presupuestos pedagógicos y sus referentes contextuales anteriores para recodificar su enfoque y diseñar un conjunto 
de herramientas didácticas que la hagan pertinente ante las variadas y desafiantes condiciones del entorno en que se implementa. La decodificación de la propuesta pedagógica parte de la relectura del proceso de investigación-acción, ya presentado, el cual se realizó en dos escenarios educativos del Centro Interactivo Maloka: los clubes de ciencia y tecnología y el trabajo en las salas del mismo museo (Franco-Avellaneda \& Altafulla, 2007; Franco-Avellaneda \& Pérez-bustos, 2008; Pérez-Bustos \& FrancoAvellaneda, 2005; Ramos et al., 2007).

La recodificación, por su parte, adquiere sentido en medio del diseño de una nueva versión del programa de clubes de ciencia y tecnología en el año 2020, inevitablemente expuesta a los ineludibles decretos de virtualización que se aplicaron a escala global en la contingencia de la pandemia. Justo allí ocurre la reconfiguración didáctica que será ejemplificada más adelante con un programa educativo que se implementa actualmente en Maloka.

\section{Producción de sentido: la recodificación de un enfoque pedagógico}

Retomar una propuesta educativa implica revisitar los presupuestos con que fue fundada para valorar y extender su vigencia y también abogar por su pertinencia en las situaciones y con los públicos a los que será enfrentada. De esta manera se puede insistir en los debates y los posicionamientos educativos que fueron presentados al inicio y que aún se requieren profundizar: (a) la no neutralidad en la producción de conocimiento científico, ni en el diseño, copia, comercialización y exhibición de los artefactos interactivos de un museo, (b) la no universalidad de los problemas abordados por las ciencias y las tecnologías, ni la de los modelos de desarrollo, producción o educación que se instalan localmente suprimiendo la diversidad y la participación política amplia, (c) la inevitable vinculación histórica y sociocultural en el proceso de emergencia, negociación y difusión de las ciencias y del pensamiento científico así como en los encuentros entre situaciones, actores y estructuras que dan lugar a las trayectorias no lineales de innovación en las prácticas científicas y tecnológicas.

Estas consideraciones aún encuentran un amplio lugar de desarrollo en la propuesta educativa re-visitada y fundamentan los tres ejes conceptuales que se describen enseguida, y los cuales se muestran en la Figura 1: 
Figura 1. Ejes conceptuales de la propuesta de cuatro momentos pedagógicos

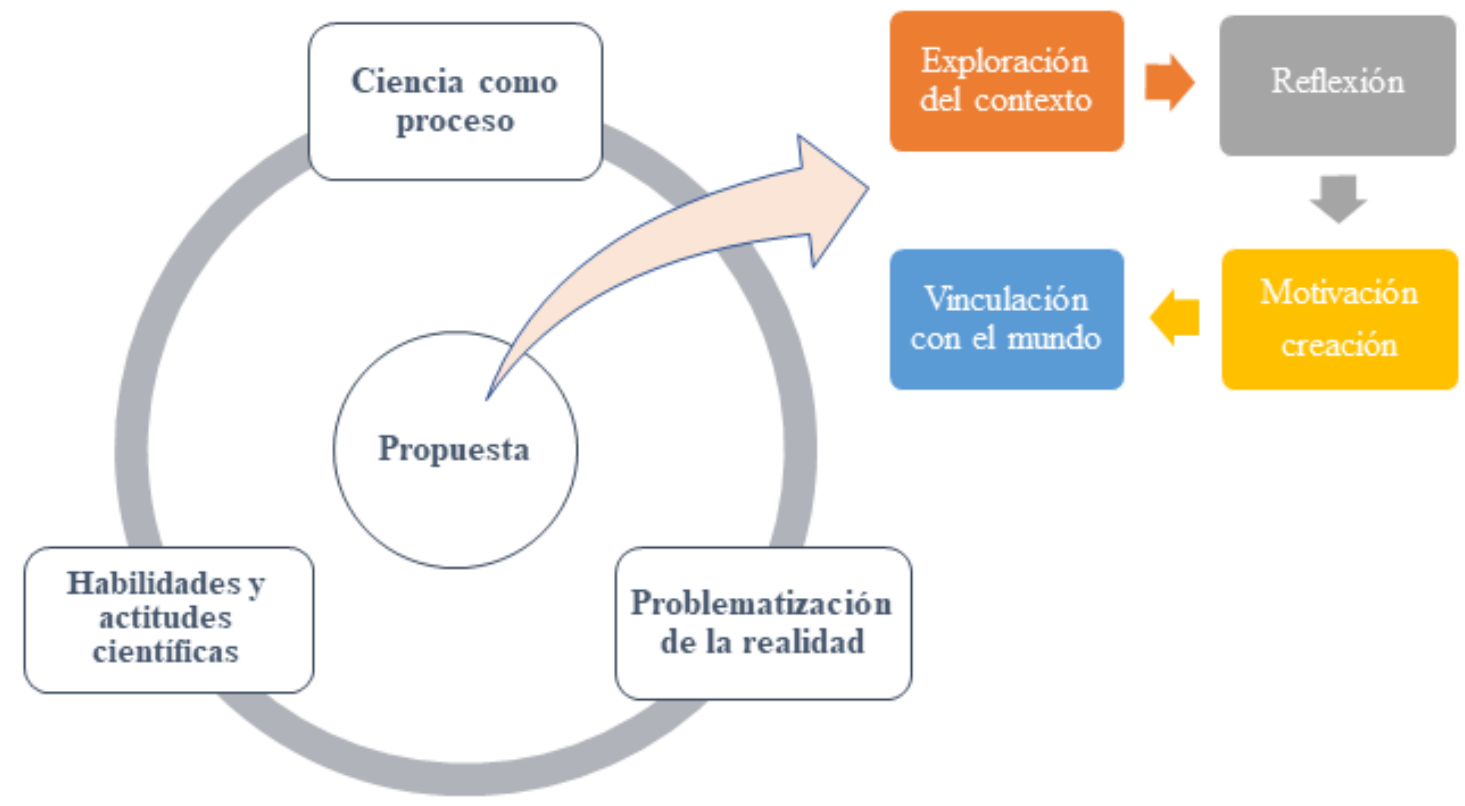

Fuente: elaboración propia.

Problematización de la realidad: El punto de partida de la propuesta de cuatro momentos pedagógicos busca reconocer los saberes previos de las personas que participan desde situaciones del entorno que componen el marco de realidad en el que están involucrados. Más que simples motivaciones para introducir un contenido específico, existe la intención de articular conocimientos científicos y circunstancias del contexto que, aunque conocidas, no pueden ser comprendidas o son mal interpretadas (Delizoicov \& Angotti, 1990). De esta manera, son desafiados a ad-mirar ${ }^{4}$ aquello que no son para comprender tanto la externalidad como el proceso de percepción que está involucrado allí (Freire, 2011).

Esa doble mirada, sobre el objeto y sobre el yo que admira, es aprovechada en el desarrollo de la experiencia educativa, porque se problematiza la curiosidad ingenua identificada como una falencia en el proceso de investigación-acción, y para ello es fundamental preguntar, elegir información y producir evidencias. Además, esta doble mirada, estimula la actualización consciente de una perspectiva previa que es transformada acudiendo a la imaginación de alternativas de relación con el mundo.

Ciencia como proceso e innovación no lineal: Uno de los propósitos educativos del museo consiste en habilitar la discusión, negociación e intercambio de ciencias y tecnologías, entendidas como producciones culturales, es decir, lo educativo se enfoca en la reflexividad y el aumento de conciencia de los actores implicados en una situación problema a la que están vinculados por intereses específicos (Freire, 2005). Esto es

4 Paulo Freire no usa la palabra admirar en el sentido de quedarse absorto o atónico ante algo, por eso separa las raíces latinas de la palabra ad-mirar para enfatizar la necesidad de ver hacia algún lugar, dirigir la mirada hacia algo. 
posible al presentar y abordar las ciencias como conocimientos en disputa (Latour, 1987). Superando una oposición superficial entre proceso y resultado se reconoce que las ciencias implican un producto, un conjunto de conocimientos y métodos, aquello que se sabe y hace parte del acervo elaborado por comunidades científicas en los últimos siglos. Esta dimensión de producto es el componente de las ciencias y las tecnologías privilegiado y más presentado en la educación formal.

Al mismo tiempo se explicita deliberadamente que las ciencias y las tecnologías implican modos de explorar y comprender la realidad — ciencia como proceso-, a través de los cuales se generan conocimientos, técnicas y artefactos, y que estos procesos ocurren de manera múltiple ${ }^{5}$, redundante y singular, lo que imposibilita una evolución lineal y sostenida, tanto de un conocimiento como de un discurso tecnológico. Esta perspectiva suele tener menos protagonismo en la educación escolar y por ello es privilegiada en la recodificación pedagógica de la actual propuesta educativa.

Habilidades y actitudes: La escuela es el lugar socialmente designado para el desarrollo de competencias científicas. En esa vía, los museos interactivos de ciencia y tecnología se han entendido como escenarios complementarios, en consecuencia, su papel se ha orientado al fortalecimiento de habilidades y actitudes requeridas en estos ámbitos. En la propuesta de cuatro momentos pedagógicos las habilidades son entendidas como un elemento clave para ser capaces de poner el conocimiento en acción, es actuar conociendo las dinámicas y límites del pensamiento. Estas habilidades no son innatas, sino que se aprenden, y no se generan en el vacío, sino que necesitan de un contenido conceptual para su desarrollo.

Asimismo, se reconoce que las habilidades no son independientes a las actitudes con las que se despliegan dichas destrezas. Esto implica una diferencia sustancial en el enfoque de las habilidades científicas respecto a los escenarios de educación formal, porque estas actitudes se comprenden impregnadas de valores, intereses y motivaciones, y por tanto de posturas políticas y éticas, y dicha perspectiva resulta indispensable para comprender los modos de producción del sentido social en los ámbitos de las ciencias, las artes y la ingeniería.

En síntesis, estos son los tres ejes que orientan el diseño de un conjunto de estrategias didácticas con las que es posible materializar buena parte de los presupuestos educativos. Tales estrategias se acoplan en un ordenamiento metodológico de cuatro momentos pedagógicos (ver Figura 1), los cuales tienen como punto de partida la propuesta original de Motivación para la creación, cuya ruta de exploración de referentes, modelación de soluciones y reflexión del proceso fue descrita previamente. Así es como la articulación de los tres ejes conceptuales conduce a un tránsito ya advertido: de motivar a partir de la problematización de la cotidianidad de las y los participantes como impulso creativo a convidarlos en una exploración consciente de su entorno, que los vinculen desde su agencia y su posicionamiento político en el mundo. Siguiendo los planteamientos freireanos "ad-mirar" la realidad significa objetivarla, aprehenderla, como campo de su acción y reflexión (Freire, 1977).

5 Desde los años 90 se ha documentado cómo se configuran procesos de innovación científico-tecnológica en lógica multidireccional. En ese sentido, ya son clásicos los trabajos sobre la bicicleta y el desarrollo de la navegación (Bijker \& Law, 1997; Law, 2001). 
Este fortalecimiento metodológico busca hacer frente a las desafiantes y cambiantes condiciones de las historias locales, incluida la precipitada reacción política y económica global, con sus consabidos desajustes socioculturales, ante las medidas contingentes tomadas en la pandemia de COVID-19. Para ejemplificar y situar las maneras en que estos momentos pedagógicos ordenan el conjunto de herramientas didácticas se hará mención del programa Chicas STEAM implementado recientemente, con motivo de la pandemia. Esto no sin antes presentar los cuatro momentos pedagógicos que constituyen el ordenamiento actualizado de la propuesta pedagógica:

1. La exploración. Con énfasis en la exploración referentes cotidianos y de contextos diversos - local, global, histórico, social, ambiental entre otros-. Hay dos enfoques en este momento: a través de la indagación directa, con preguntas provocadoras que lleven a quienes participantes a pensar en su cotidianidad estética, tecnológica y científica y a través de actividades que cuestionen los referentes que los participantes tienen respecto a un tema, que les permitan verlo desde otros puntos de vista. Este momento se opone a la idea generalizada en los museos interactivos, que asumen la cotidianidad de los participantes como algo detenido, estático y separado de la experiencia existencial. Así, bajo el mandato de lo cotidiano se borra el sujeto y adquiere fuerza la sonoridad narrativa y no la posibilidad de transformación, en una visión bancaria de lo educativo (Freire, 2005).

2. La reflexión. Esta se ha concebido como un punto de inflexión en el que colectivamente se confrontan los enunciados, los conceptos y las estructuras para indagar en la forma en que han sido producidos. Algunas veces la reflexión acude a una revisión histórica que pone en contexto un enunciado científico y otras veces se apoya en las controversias que dan lugar al posicionamiento de ciertas ideas por encima de otras alternativas, como el caso de la definición de un estándar de red eléctrica, la estandarización de una escala de medida o el uso de un medio de transporte sobre otro. Esto significa un intercambio cultural entre todas las personas que participan, otorgando valor a los conocimientos adquiridos por los y las chicas en su medio cultural y haciendo una oposición al reproductivismo. Además, esto reconoce la existencia de un sujeto colectivo (Freire, 1977), porque los sujetos no están aislados en el mundo y es el colectivo (sociedad) que debe apropiarse del conocimiento científico para democratizarlo, buscando la configuración de alternativas de desarrollo.

3. Motivación y creación. Con la reflexión se configuran las condiciones para probar, los referentes y las perspectivas ampliadas producto de la problematización inicial, en una actividad que está implicada en el hacer, en pensar con las manos. Para ello se sigue la siguiente secuencia: dimensionar el problema-desafío ${ }^{6}$ sobre el cual se van a plantear diversas comprensiones

6 Estos problemas-desafíos guardan relación con las situaciones límite propuestas por Freire (2005). 
ampliando el marco de referencias, planear la aplicación de procedimientos para abordar las alternativas de actuación y recoger el proceso identificando los aprendizajes de este recorrido y sus hallazgos. Por eso es necesario reconocer los intereses de niños y niñas a través de una pesquisa que pondere los temas a ser abordados, interponiendo intereses comunes por encima de los particulares. Esto permite a la propuesta pedagógica interpelar múltiples sujetos y sobre todo dejar germinar muchas propuestas de transformación.

4. Vinculación con el mundo. En este punto se recoge la experiencia del participante en el proceso de creación, así como la manera en que los referentes estéticos, científicos y tecnológicos se han cuestionado, fortalecido o transformado, pasando por los contextos, lo conceptual y la práctica planeada y documentada. En la vinculación con el mundo sucede lo metacognitivo, es decir que nos hace volver sobre lo aprendido y nos permite aprehenderlo, pues lo vemos desde nuestra experiencia. De esta manera ocurre la articulación del proceso al retomar con los y las participantes las preguntas iniciales y mirar lo que pasó, así como cuando colectivamente se recoge la experiencia, en tanto proceso de creación, analizando la transformación de sus compresiones. Además, este cierre implica un aumento de conciencia de los y las participantes de la experiencia, pues a través de comparar resultados obtenidos y realimentar lo vivido se configuran las condiciones de posibilidad para acciones de cambio o reconocimiento, que potencialmente habilitan otras maneras de actuar en el mundo.

\section{A manera de ejemplo: Programa Chicas STEAM ${ }^{7}$}

El programa Chicas STEAM es una iniciativa conjunta entre el Museo Interactivo Maloka y el Ministerio de Tecnologías de la Información y las Comunicaciones de Colombia (MinTIC) para la formación y mentoría de alrededor de 6500 niñas, adolescentes y jóvenes entre los 12 y 15 años de edad de los 32 departamentos de Colombia, en campos relacionados con la ciencia, la tecnología, la ingeniería, las artes y las matemáticas, que corresponden al término STEAM, por sus siglas en inglés. Este proyecto educativo se realiza en doce semanas, en contra-jornada escolar, mediante herramientas de comunicación por internet y está dirigido por mediadores de Maloka, que son profesionales en diversos campos de las ciencias, ingenierías, licenciaturas y humanidades; así mimo acompañan un grupo de mentoras voluntarias compuesto por mujeres científicas, artistas e ingenieras, emprendedoras con amplia trayectoria académica y profesional.

\section{Devorarse el término STEM/STEAM}

El término STEAM, que da nombre a este programa, es el resultado de un acuerdo estratégico entre las entidades que financian este programa ya que esto les permite conciliar sus intereses institucionales. Para el Museo Interactivo Maloka se trata de

7 Ver: https://www.maloka.org/convocatoria-chicas-steam-2021 
desarrollar estrategias de apropiación social del conocimiento científico-tecnológico. En cuanto a MinTIC sus esfuerzos se orientan a la promoción del uso efectivo y la apropiación masiva de las Tecnologías de la Información y la Comunicación (TIC). En ese sentido, el acuerdo entre las dos entidades convoca sus agendas políticas hacia un término común, vigente y con reconocimiento global en los ámbitos económico, político, cultural y educativo.

En este marco estratégico es donde la propuesta de los clubes de ciencia y tecnología encuentra su escenario más desafiante, pues el despliegue educativo demanda la producción de un sentido contextualizado para el término STEAM, a sabiendas de que esto define parcialmente el alcance de la recodificación de los tres ejes conceptuales ya expuestos: (a) problematización dela realidad delos participantes y su entorno, (b) ciencias y tecnologías como producciones culturales que devienen de procesos en trayectorias múltiples, (c) fortalecimiento de habilidades científicas y vinculación explícita con los principios, valores y posturas políticas y éticas con las que se implementan.

Esta controversial asociación de la propuesta educativa con el término STEAM animó a seguir aquella metáfora suscrita por el movimiento antropofágico brasilero, que casi un siglo atrás proponía devorar los modelos hegemónicos del cubismo y el futurismo europeos para recodificarlos desde las entrañas insaciables del territorio americano, caníbal y exótico. Ese movimiento antropófago, cifradamente descrito por Oswald de Andrade, le hace frente al discurso cultural dominante de la Europa imperial que abrazaba el inicio del siglo XX y que negaba la reproducción de esa historia: "Teníamos la justicia, codificación de la venganza. La ciencia, codificación de la magia. Antropofagia. La transformación permanente del Tabú en tótem" (De Andrade, 1928, p. 2). Con el manifiesto antropofágico se actualiza en el presente una estrategia que devora la línea histórica universal para producir algo múltiple, extraño, ese otro que deviene agencia y única alternativa ética posible (Miller, 2006).

Así pues, devorarse el término STEAM implica engullir la historia de los modelos económicos, políticos y culturales que lo producen, pues sabemos que el acrónimo es un producto y no el fundamento. Por esta razón, en el nombre de este artículo los proyectos globales hacen referencia, entre otras cosas, a los discursos colonizantes a los que la propuesta educativa se enfrenta, motivado entretanto por múltiples historias locales que encarnan cuestionamientos éticos desde los que se interrumpe la producción de una identidad universal.

El acrónimo SME\&T, SMET o STEM hace parte de estos discursos globales problemáticos. El término es la fórmula inaugural con la que la National Science Foundation (NSF) en Estados Unidos designó en la década de los 90 la congregación de cuatro campos disciplinares: Science, Technology, Engineering and Mathematics. El uso sostenido de un acrónimo devela las diferencias epistémicas irreconciliables entre los campos que impiden acoplarlas en una sola identidad, además, variadas revisiones hallan un conjunto de dificultades de unificación conceptual y déficits en sus aportes al ámbito de la educación científico-tecnológica (Toma \& García-Carmona, 2021). 
La revisión de literatura hecha por Toma y García-Carmona ofrece varias aproximaciones para el cuestionamiento del término STEM y sus variantes ${ }^{8}$. Para empezar, la dispersión en tantos acrónimos hace difícil vincular estos términos en los planes de estudio y en las prácticas educativas, asunto que se deriva de los pobres estudios empíricos y marcos teóricos que orientan esa tarea (Honey et al., 2014). El abuso de estos términos para el desarrollo de políticas educativas en las mismas áreas los reduce a la instrumentalización como medio para incrementar la competitividad económica estadounidense y promocionar la profesionalización en estos campos (Breiner et al., 2012).

La trayectoria del término STEM en el ámbito educativo ha merecido valoraciones similares o más contundentes. Domènech-Casal (2018) afirma que el término STEM representa un objetivo político, no un enfoque pedagógico o didáctico, aunque los emplee para promover sus propósitos. Además, como lo mencionan Toma y GarcíaCarmona (2021), existe un problema estructural en el sistema educativo mundial para la implementación de STEM pues se cuenta con organizaciones curriculares fieles a los modelos del auge industrial de los siglos XIX y XX que no favorecen enfoques interdisciplinarios o integrados, y con ello un déficit en la formación de docentes, tanto en educación primaria como secundaria, especialmente en cuanto al conocimiento del contenido y al conocimiento didáctico del contenido.

El enfoque CTS cuenta con mayor madurez conceptual y esfuerzos deliberados de desarrollo didáctico que en América Latina han estado interpelados desde la propuesta educativa freireana (Auler \& Delizoicov, 2006; Delizoicov \& Auler, 2011; FrancoAvellaneda, 2013a; Franco-Avellaneda \& Von-Linsingen, 2011). Esta aproximación del abordaje freireano al enfoque CTS haría que el uso de este término resulte más pertinente para la definición de la propuesta educativa, sin embargo, señalamos antes que el acuerdo político entre las entidades formuladoras del Programa Chicas STEAM optó por un término-slogan de mayor visibilidad y globalmente validado. Así, el desarrollo de la propuesta al interior del programa chicas STEAM, se declara antropófago del término STEAM, y la recodificación del enfoque pedagógico, descrita en los apartados anteriores se extendió a la resignificación del término STEAM que se usa como paraguas y fue integrado como condición del contexto de implementación, así como se integró la estrategia de despliegue del programa por internet en formato on-line.

En cuanto a la condición diferencial del acrónimo STEAM con la letra 'A' que hace referencia al componente artístico, vale anotar que como acrónimo sigue arrastrando el problema de la aglomeración de áreas de conocimiento mediante una definición superficial que carece de desarrollo educativo; no obstante, permitió tensionar las relaciones entre epistemes claramente diferenciadas. La revisión hecha por Krug y Shaw (2016) sobre la integración de las artes y las humanidades al término STEM recae en varios lugares comunes. Refuerza la idea de que estas áreas asisten al movimiento STEM, es decir, que estarían a su servicio para el desarrollo de las habilidades científicas

8 Agrupado al arte: STEAM/STEM+A; a la imaginación: iSTEAM; al arte y la robótica: STREAM; a la sostenibilidad y la integración curricular: $\mathrm{ST}^{\oplus} \mathrm{E}(\mathrm{A}) \mathrm{M}(\mathrm{S})$. 
y tecnológicas, aportando la creatividad necesaria para innovar en esas mismas áreas y ofreciendo mejoras en la cognición, la atención y el aprendizaje de sus integrantes, incluso retoman investigaciones que afirman que las artes contribuyen al "desarrollo de habilidades para la vida, el fomento del pensamiento crítico, el cuestionamiento de la autoridad y la promoción de la creatividad, la resolución de problemas, la curiosidad y la flexibilidad." (Krug \& Shaw, 2016, p. 194).

Si bien todas estas afirmaciones tienen sustento investigativo coinciden en reducir las artes a un lugar asistencial en el que son despojadas de su capacidad de producción de conocimiento auténtico e independiente. Al desconocerlo también se omite fomentar el desarrollo de habilidades en este campo y no se asume como un modelo de rol para estudiantes o docentes que los usan.

Dentro del programa se considera vital la práctica artística pues permite percibir, comprender y apropiarse del mundo a partir de diversos conocimientos, medios y habilidades que son aplicables tanto al campo artístico, como a las otras áreas del conocimiento. La expresión artística permite diseñar y apropiar herramientas para representar el mundo y generar una mayor sensibilidad y agencia. Las participantes se permiten y son conscientes de afectarse a sí mismas y afectar a las otras por medio de su hacer. Así, las artes permiten imaginar inéditos viables, son estas utopías que se transforman en posibilidades a través de la creación artística —inéditos viables(Freire, 2005).

Esta amplia problematización de las amalgamas interdisciplinares que producen los acrónimos STEM y STEAM se aprovecha como fermento crítico para la recodificación del enfoque pedagógico y didáctico del programa, asunto que revisaremos a continuación.

\section{La propuesta educativa en el Programa Chicas STEAM}

El proyecto de Chicas STEAM se justifica en la apuesta intencionada de abordar: (a) el sesgo de género y su dimensión histórica que ha caracterizado a las áreas STEAM, el cual ha privilegiado una mayor participación y visibilidad de los hombres y de lo masculino en estas áreas, (b) la construcción de espacios seguros para las chicas que contribuyan a trabajar en pro de la eliminación de dicho sesgo, (c) la necesidad de reconfigurar los roles de género que caracterizan a las sociedades patriarcales y machistas.

Así, el propósito pedagógico de este programa más allá de promover vocaciones y promocionar las áreas STEAM, busca incidir en el autorreconocimiento de las destrezas, inteligencias y capacidades que las participantes traen consigo para producir conocimiento e incluir sus preguntas vitales en estas áreas como parte de su proceso de construcción de identidad. El horizonte de actuación del programa desafía a las niñas y jóvenes a proponer iniciativas para transformar su entorno, las cuales se fundan desde sus propios intereses y necesidades en diálogo con necesidades y situaciones del contexto, siguiendo la lógica del enfoque Ciencia, Tecnología y Sociedad (CTS), porque sus actuaciones sitúan el pensamiento científico y matemático y la práctica tecnológica $\mathrm{y}$ artística en las diferentes realidades que viven las participantes. 
Para ello, se generan ambientes seguros de aprendizaje para la exploración vocacional de las niñas y jóvenes en las áreas STEAM, permitiendo a las participantes vincularse a procesos que complementan su formación integral y las reconoce políticamente como ciudadanas del siglo XXI. En este caso, respecto a las dificultades de unificación conceptual y déficit en desarrollo educativo de los términos STEM y STEAM se privilegian acciones pedagógicas que presenten las ciencias y tecnologías como procesos y conocimientos en acción, es decir, como campos de debate y argumentación vinculados con el mundo que rodea a las participantes (Latour, 1987) articulados con una producción de sentido crítico respecto a las circunstancias del contexto y a las perspectivas que se transforman en relación con él (Delizoicov \& Angotti, 1990; Freire, 2011).

También se problematiza el lugar relegado e instrumental de las artes y se opta por privilegiar las acciones pedagógicas que reconocen el valor de intercambio entre las áreas del acrónimo STEM y los procesos y prácticas artísticas. Superando el lugar asistencial de las artes como campo de exclusiva promoción a la creatividad, la innovación y el pensamiento crítico en otras áreas disciplinares, se integra como campo cognitivo y se reconoce su agencia política como perspectiva alterna de vinculación al contexto y construcción de relaciones históricas y culturales relevantes que habilitan otras formas de exploración y aproximación al conocimiento de la realidad (Acosta-Sierra, 2019).

Laimplementación del programa pone en acciónlos cuatro momentos pedagógicos a través de cinco estrategias: guías de actividades autónomas, acompañamiento, encuentros en línea, mentoría y actividades con familias y docentes. En la figura 2 se han relacionado los momentos con las estrategias precisando la manera en que se llevan a cabo. En negrita se resaltan algunas herramientas concretas que emplea el programa, como la plataforma virtual que permite interacciones sincrónicas y asincrónicas y una caja de herramientas que se entrega a cada participante durante su vinculación a los clubes. 
Figura 2. Estructura educativa del programa Chicas STEAM, Maloka, 2020

\begin{tabular}{|c|c|c|c|c|c|}
\hline \multirow[b]{2}{*}{$\begin{array}{l}\text { Momentos } \\
\text { pedagógicos }\end{array}$} & \multicolumn{5}{|c|}{ Estrategias didácticas } \\
\hline & Autoformación & Acompañamiento & $\begin{array}{l}\text { Encuentros en } \\
\text { línea }\end{array}$ & Mentoría & $\begin{array}{l}\text { Familias y } \\
\text { docentes }\end{array}$ \\
\hline $\begin{array}{l}\text { Exploración } \\
\text { de referentes } \\
\text { cotidianos } \\
\text { y contextos } \\
\text { diversos }\end{array}$ & $\begin{array}{l}\text {-Podcast y } \\
\text { videos que } \\
\text { narran historias } \\
\text {-Plataforma } \\
\text { digital con } \\
\text { recursos } \\
\text { hipermedia }\end{array}$ & \multirow{3}{*}{$\begin{array}{l}\text {-Llamadas } \\
\text { telefónicas de } \\
\text { mediadores } \\
\text {-Call center de } \\
\text { Maloka }\end{array}$} & \multirow{2}{*}{$\begin{array}{l}\text {-Sesiones vía } \\
\text { Zoom de hora } \\
\text { y media } \\
\text {-Talleres } \\
\text { temáticos } \\
\text { dependen de } \\
\text { los intereses de } \\
\text { las chicas }\end{array}$} & $\begin{array}{l}\text {-Intercambio } \\
\text { de } \\
\text { experiencias } \\
\text { de vida con } \\
\text { las mujeres } \\
\text { mentoras }\end{array}$ & $\begin{array}{l}\text {-La casa como } \\
\text { estación de } \\
\text { exploración } \\
\text { del mundo } \\
\text { (contexto de } \\
\text { cuarentenas) }\end{array}$ \\
\hline $\begin{array}{l}\text { Reflexión } \\
\text { sobre la } \\
\text { producción de } \\
\text { conocimiento }\end{array}$ & $\begin{array}{l}\text {-Controversias y } \\
\text { debates en foros } \\
\text { y chat }\end{array}$ & & & $\begin{array}{l}\text {-Discusiones } \\
\text { sobre la } \\
\text { pertinencia } \\
\text { social }\end{array}$ & $\begin{array}{l}\text {-Conocimiento } \\
\text { en disputa con } \\
\text { perspectivas } \\
\text { culturales y } \\
\text { ancestrales }\end{array}$ \\
\hline $\begin{array}{l}\text { Motivación y } \\
\text { creación con } \\
\text { materiales } \\
\text { concretos }\end{array}$ & $\begin{array}{l}\text {-Guías para } \\
\text { "pensar con las } \\
\text { manos" } \\
\text {-Uso de } \\
\text { una caja de } \\
\text { herramientas }\end{array}$ & & $\begin{array}{l}\text {-Guion que } \\
\text { orienta la } \\
\text { mediación, } \\
\text { con propósito } \\
\text { y metodología } \\
\text { definidos. }\end{array}$ & $\begin{array}{l}\text {-Colegaje en } \\
\text { los procesos } \\
\text { de creación }\end{array}$ & $\begin{array}{l}\text {-Planes que } \\
\text { expanden } \\
\text { la caja de } \\
\text { herramientas y } \\
\text { vinculan otros } \\
\text { recursos }\end{array}$ \\
\hline $\begin{array}{l}\text { Vinculación } \\
\text { con el mundo: } \\
\text { alternativas de } \\
\text { actuación }\end{array}$ & $\begin{array}{l}\text {-Presentación } \\
\text { de situaciones- } \\
\text { problema } \\
\text { locales } \\
\text {-Bitácoras como } \\
\text { memoria del } \\
\text { proceso }\end{array}$ & -Mailing de enlace & $\begin{array}{l}\text {-Guion para } \\
\text { el intercambio } \\
\text { de las } \\
\text { experiencias de } \\
\text { autoformación }\end{array}$ & $\begin{array}{l}\text {-Planes para } \mathrm{t} \\
\text { entorno. } \\
\text {-Alianzas que } \\
\text { cambios (tran }\end{array}$ & $\begin{array}{l}\text { ransformar el } \\
\text { sostienen } \\
\text { sformaciones) }\end{array}$ \\
\hline
\end{tabular}

Fuente: Elaboración propia.

El diseño de las guías de autoformación contempla un extenso trabajo de articulación de referentes en recursos hipermedia asociados a esfuerzos de diseño universal que permiten disponer de formatos alternos auditivos, visuales y lecto-escritos. En cuanto a la selección temática se privilegiaron las comprensiones transversales que están presentes en las ciencias, las matemáticas y las tecnologías, ya sea que se estén estudiando grupos originarios, el COVID-19 o una celda de combustible. Cuatro nociones: sistemas, modelos, escala y constancia y cambio, son ideas que trascienden los límites disciplinares y se reconvierten en explicaciones, teorías, observaciones y diseños (Rutherford, 1997). A partir de ese enfoque se diseñan contenidos de exploración que emplean como excusa conceptos y procesos de las ciencias, las tecnologías y las artes, 
como son evolución, genética de poblaciones, mezclas y combinaciones, modelos matemáticos, medidas y proporciones, percepción sensorial, escalas de tiempo, sistemas electrónicos, interpretación y expresión artística, programación algorítmica, cambios de temperatura, dinámica de ecosistemas, entre otros.

En cuanto a la problematización de la realidad se seleccionaron diferentes formatos para contextualizar las tensiones entreámbitos culturales, políticos, económicos y cognitivos entretejidos con las temáticas propuestas. Con ese motivo se estimula la exploración de casos controversiales, como la mercantilización de la investigación científica en medio de la urgencia por la producción de vacunas, o los esfuerzos sociales, políticos, científicos y tecnológicos implicados en la búsqueda de personas desaparecidas por el conflicto armado colombiano. Asimismo, se proponen ejercicios de exploración y práctica interdisciplinar como el trabajo de investigación sociológica y epistémica de la fotografía de Angélica Dass o del fotógrafo ciego Evgen Bavčar.

Este conjunto de recursos se organiza en una malla de contenidos del programa que pone su mayor atención en las rutas de exploración e identificación de preguntas vitales de las niñas participantes. Tales preguntas orientan la búsqueda autónoma de referentes, el intercambio con las mujeres mentoras, la vinculación con actores locales y la construcción de alianzas. La estrategia didáctica que recoge este recorrido y las acciones de transformación del entorno que proyectan las participantes es un misceláneo de esquemas, modelos, mapas de navegación, bocetos y otras producciones que las niñas materializan en sus bitácoras.

El seguimiento a la experiencia de las participantes se realiza mediante diferentes estrategias de acompañamiento con las que se recoge información diversa sobre su quehacer en los clubes, desde su comprensión para el desarrollo de las actividades hasta las emociones desencadenadas y las transformaciones de su relación con el entorno y con la producción de conocimiento. Esto ocurre en medio de un intercambio en el que los mediadores proporcionan apoyo y orientación a las niñas y jóvenes en el desarrollo de esas actividades en sus casas y reciben de ellas impresiones, cuestionamientos, intereses y preocupaciones. Para este seguimiento es fundamental el encuentro con los saberes previos de las participantes y el intercambio de preguntas que promuevan la discusión, la problematización de la realidad y el reconocimiento de las habilidades y las actitudes que pueden ser aprendidas y transformadas.

Por su parte, el reconocimiento de los procesos de reflexión y actuación en contexto ocurre durante el proceso de exploración e identificación de las preguntas vitales que las niñas participantes postulan en el programa. Tales preguntas orientan la búsqueda de referentes, el intercambio con las mujeres mentoras y con los docentes, la vinculación de otros actores y la construcción de alianzas en un esfuerzo de planeación de proyectos CTS. El alcance de este componente es la identificación y la asociación de esas ideas de interés en una gama de posibilidades para actuar en su entorno cercano. Este proceso se despliega mediante diversos formatos para elaboración de bitácoras y cuadernos de artista que las participantes desarrollan a lo largo del programa y que permiten más adelante la colectivización de tales ideas en campos de exploración, investigación y acción. 
Finalmente, la plataforma digital que recoge gran parte de los recursos mencionados en diversos formatos, tanto de contenido, como de enfoque pedagógico y estrategia didáctica, configura una ruta de diseño didáctico que enriquece las formas convencionales de transmisión pasivas y unidireccionales de conocimiento en las que el centro de gravedad está en el formador, como experto en un contenido que se transmite, en tanto el participante queda relegado a un rol pasivo de receptor. Para ello los recursos digitales y concretos se diseñan en lógica de incompletitud, en otros términos, las participantes deben aportar su exploración y comprometer sus ideas previas para emprender el intercambio de experiencias en los encuentros sincrónicos y asincrónicos. Este es un desafío abierto a la subordinación habitual del propósito pedagógico ante la arquitectura de los sistemas técnicos que implicó la recodificación de las funcionalidades de un Learning Management System (LMS), de un gestor de contenidos hipermedia y de una aplicación de chat que sobre la que se realiza el acompañamiento asincrónico del proceso educativo.

\section{A manera de conclusión: retornar al punto de partida para emprender otra caminada}

En este artículo se presentó la génesis, desarrollo y consolidación de una propuesta de cuatro momentos pedagógicos, la cual se fundamenta en los planteamientos de Freire y los estudios sociales de la ciencia y la tecnología. A partir de esos planteamientos, la propuesta muestra cómo sería posible pensar otro tipo de popularización del conocimiento tecnocientífico más acorde con la realidad específica de nuestras sociedades, y en consecuencia se posiciona una visión de apropiación social en lógica de intercambio, combinación y diálogo entre diferentes tipos de conocimientos, entre los cuáles la ciencia y la tecnología constituyen una parte fundamental de la mirada de posibilidades, pero no su totalidad. Finalmente, explícita de manera deliberada: temas, materialidades y escenarios que se configuran en mediadores, informadores, educadores, etc., de los procesos de negociación social entre conocimientos y saberes científicos y no-científicos (Franco-Avellaneda \& Pérez-Bustos, 2010).

En ese sentido la propuesta educativa presentada permite identificar dos conclusiones clave a la hora de poner en acción propuesta educativas. De un lado, se reconoce que las prácticas educativas no son trasplantadas sino reelaboradas, y por eso ocurren hibridaciones permanentes que rompen la polaridad entre modernización y tradición, dependencia y nacionalismo, global y local, etc. Aquí lo importante, en lógica antropofágica, es reconocer que ideas de diferente índole se yuxtaponen no con objetivo de pureza sino con la intención de superar una situación límite que se entiende como central en la transformación de nuestros contextos (Freire, 2005).

De otro lado, el programa Chicas STEAM muestra la vigencia de la propuesta educativa freireana y sus posibilidades de reelaboración en la medida en que pone en juego: dialogicidad, problematización, concientización, ciencia como proceso y ciencias y género. Articulación que cobra sentido para niñas y jóvenes que identifican 
sus posibilidades de vinculación con el mundo, a partir de un proceso reflexivo sobre su contexto y el consecuente aumento de conciencia sobre sus posibilidades de acción como integrantes activas de una sociedad.

Esas constataciones, sobre los procesos de apropiación de conocimiento en nuestras sociedades cobra relevancia en el panorama actual de contingencia por causa de la pandemia, pues se hace evidente la necesidad de replantear los espacios de escolarización, los contenidos, las estrategias didácticas y los recursos materiales para la educación de manera que ayuden a cerrar las brechas de aprendizaje que se han ampliado en el actual contexto (Porras, 2021). Además, hoy ya sabemos, que sí es posible parar y problematizar los discursos desarrollistas que se amparaban en la imposibilidad de frenar el tren del progreso, asunto que quedó en suspenso - literalmente-, con la llegada del virus SARS-CoV-2 en todas las escalas del comercio, la producción, y por supuesto, de los sistemas educativos planetarios.

$\mathrm{Al}$ inicio de esta pandemia, Bruno Latour propuso como ejercicio colectivo imaginar las medidas de protección para evitar el regreso al modelo de producción anterior a la crisis (Latour, 2020). En el marco de esta propuesta hizo algunas preguntas, entre las que estaban: ¿qué actividades de las suspendidas no queremos que vuelvan?, ¿qué transición imaginar para las personas que viven de esas actividades?, ¿qué actividades de las suspendidas queremos que se reanuden?, ¿cómo ayudar a que se reanuden? Esta desaceleración, quizás pueda ser un momento para comprometernos con la transformación de nuestras realidades, no solo imaginarlas. Así, esta es la oportunidad para decir que sí queremos que reabran los museos interactivos, pero también queremos que sean mejores. Hay que conseguir que los museos se comprometan y contribuyan abiertamente con la superación de inequidades de países como Brasil y Colombia, debemos hacerlo con los medios que tenemos hoy disponibles, y hay que insistir en que deben ser espacios para la conversación y el diálogo, y sobre todo para pensarnos y vernos en comunidad (Freire, 1979).

Ahora bien, la matriz material disponible para interrumpir el actual modelo de desarrollo que destruye ecosistemas y pueblos y configura inequidades económicas, políticas y culturales, es la misma gramática con la que se escriben las condiciones de posibilidad para transformar nuestra realidad. Es decir, por ahora, no contamos con otras alternativas de herramientas tecnológicas porque justamente las que se han priorizado son aquellas enfocadas en el productivismo. La evidencia de ello es que en el ambiente educativo se están empleando un sinnúmero de plataformas de comunicación creadas en lógica de racionalidad productivista o adaptadas recientemente para los modelos instruccionales de educación en línea.

Aun así, es esa gramática la que debe ser alterada en el ejercicio mismo de la escritura, con acciones deliberadas como hacer de la habitación un taller para desarmar aparatos, montar en la sala un teatro de sombras, compartir la cocina con un laboratorio de química o fundar una estación de observación de aves en el patio de la casa. En otros términos, la «domesticación» de lo educativo (Ines Dussel, 2020), pues se trata de afrontar 
la paradoja educativa de la cuarentena: asumir el decreto global de la virtualidad para conseguir que los aprendices salgan de las pantallas y se vinculen de manera auténtica con el mundo en que viven.

Es en ese mismo sentido que las plataformas digitales empleadas para operar la propuesta de cuatro momentos pedagógicos provienen del desmantelamiento y la decodificación de las tecnologías disponibles en el entorno productivo y de la empresa masiva de educación en línea. Se trata de reconfigurar un ambiente educativo desafiando una subordinación bien conocida que es la del sistema técnico sobre el propósito pedagógico. Lo que esto implica en el orden de diseño es que primero ocurre la escritura de una malla de contenidos, de las guías de autoformación y de los modelos de mediación, para luego seleccionar los acoples de las funcionalidades en las plataformas digitales que materializan la estrategia didáctica.

Lo anterior deja expuesta una de las más importantes conclusiones de la propuesta pedagógica aquí presentada, la educación como proceso de humanización no sólo define lo que aprendemos y el propósito de aprenderlo, sino que también establece a través de qué lo aprendemos. De esta forma estamos conociendo y aprendiendo a ser en el mundo: a través de objetos, relaciones, acoples, desmontajes, historias y controversias.

\section{Referencias}

Acosta-Sierra, P. H. (2019). Justicia [poética] y memoria [inquietante]. Universidad Pedagógica Nacional. http://hdl.handle.net/20.500.12209/9673

Allen, S., \& Gutwill, J. (2004). Designing science museum exhibits with multiple interactive features: five common pitfalls. Curator, 47(2), 199-212. https://doi. org/10.1111/j.2151-6952.2004.tb00117.x

Arroyo, M., Ibarra, C., \& Razo, A. (2011). La nueva museología en México. En L. F. Rico (Ed.), Aportaciones a la museología mexicana (pp. 11-30). Dirección General de Divulgación de la Ciencia - UNAM.

Auler, D., \& Delizoicov, D. (2006). Ciência-Tecnologia-Sociedade: relações estabelecidas por professores de ciências. Revista Electrónica de Enseñanza de las Ciencias, 5(2), 337355. http://reec.uvigo.es/volumenes/volumen5/ART8_Vol5_N2.pdf

Beetlestone, J. G., Johnson, C. H., Quin, M., \& White, H. (1998). The Science Center Movement: contexts, practice, next challenges. Public Understand Science, 1(7), 5-26. https://doi.org/10.1177\%2F096366259800700101

Bonatto, M. P. (2012). A criação dos centros interativo de ciência e tecnologia e as políticas públicas no Brasil: uma contribuição para o campo das ciências, da vida e da saúde (Tese de Doutorado, Fundação Oswaldo Cruz, Escola Nacional de Saúde Pública Sergio Arouca, Rio de Janeiro, Rio de Janeiro). Repositório Institucional da Fiocruz. https://www.arca.fiocruz.br/handle/icict/14454 
Bradburne, J. M. (1998). Dinosaurs and White Elephants: the Science Centre in the 21st Century. Museum Management and Curatorship, 17(2), 119-137. https://doi. org/10.1080/09647779800201702

Braybrooke, K., \& Smith, A. (2018). Liberatory technologies for whom? Exploring a new generation of makerspaces defined by institutional encounters. Jounal of Peer Production, 3(12), 1-13. https://ssrn.com/abstract=3210701

Breiner, J. M., Harkness, S. S., Johnson, C. C., \& Koehler, C. M. (2012). What Is STEM? A Discussion About Conceptions of STEM in Education and Partnerships. School Science and Mathematics, 112(1), 3-11. https://doi.org/10.1111/j.1949-8594.2011.00109.x

Castellanos, P., Daza, S., Reyes, J., \& Reyes, M. (2009). Maloka 10 años: una mirada diagnóstica. Panamericana Formas e Impresos S. A.

Charter, M. (2018). Repair Cafes. Jounal of Peer Production, 3(12), 37-45.

Chavot, P., \& Masseran, A. (2010). Engagement et citoyenneté scientifique: quels enjeux avec quels dispositifs?. Questions de communication, 1(17), 81-106. https://doi. org/10.4000/questionsdecommunication.374

Coimbra, C., Cazelli, S., Falcão, D., \& Valente, E. (2012). Tipos de audiência segundo a autonomia sociocultural e sua utilidade em programas de divulgação. Revista Tempo Brasileiro, 1(188), 113-124.

Colciencias (2005). Política de apropiación social de la ciencia, la tecnología y la innovación. https://minciencias.gov.co/sites/default/files/ckeditor_files/Politicaascyt.pdf

Costantin, A. C. C. (2001). Museus interativos de ciências: Espaços complementares de educação. O surgimento da primeira instituição brasileira (Tese de Doutorado, Universidade Federal do Rio de Janeiro, Rio de Janeiro, Rio de Janeiro).

Daza, S., Arboleda, T., Rivera, Á., Bucheli, V., \& Alzate, J. (2006). Evaluación de las actividades de comunicación pública de la ciencia y la tecnología en el sistema nacional de ciencia y tecnología colombiano. OCyT.

De Andrade, O. (1928). Manifiesto Antropófago. Revista de Antropofagia.

Delizoicov, D. (1982). Concepção problematizadora para o ensino de ciências na educação formal. USP.

Delizoicov, D. (2008). La educación en ciencias y la perspectiva de Paulo Freire. Alexandria: Revista de Educação em Ciência e Tecnologia, 1(2), 37-62. https://periodicos. ufsc.br/index.php/alexandria/article/view/37486

Delizoicov, D., \& Angotti, J. (1990). Metodologia do ensino de ciências. Cortez.

Delizoicov, D., Angotti, J., \& Pernambuco, M. (2007). Ensino de ciências: fundamentos e métodos (2a ed.). Cortez. 
Delizoicov, D., \& Auler, D. (2011). Ciência, tecnologia e formação social do espaço: questões sobre a não-neutralidade. Alexandria: Revista de Educação em Ciência e Tecnologia, 4(2), 247-273. https://periodicos.ufsc.br/index.php/alexandria/article/ view/37690

Domènech-Casal, J. (2018). Aprendizaje Basado en Proyectos en el marco STEM. Componentes didácticas para la Competencia Científica. Ápice: Revista de Educación Científica, 2(2), 29-42. https://doi.org/10.17979/arec.2018.2.2.4524

Dussel, E. (1995). Introducción a la filosofía de la liberación. Editorial Nueva América.

Dussel, Ines. (2020). La clase en pantuflas. En Inés Dussel, P. Ferrante, \& D. Pulfer (Eds.), Pensar la educación en tiempos de pandemia: entre la emergencia, el compromiso y la espera (pp. 337-350). UNIPE Editorial Universitaria.

Falcão, D., Coimbra, C., \& Cazelli, S. (2010). Museus de ciência e tecnologia e inclusão social. En M. Granato, C. dos Santos \& M. Loureiro (Eds.), O Caráter Político dos Museus (Vol. 12, pp. 89-116). MAST. http://livroaberto.ibict.br/handle/1/955

Fernández-Guido, H. (1973). Informe del director de la Mesa Redonda de Santiago de Chile. Mesa redonda sobre el desarrollo y el papel de los museos en el mundo contemporaneo.

Franco-Avellaneda, M. (02-05 de julho, 2013a). Ensamblar museos interactivos: prácticas, actores y artefactos. VI Encontro de jovens investigadores de estudos sociais e políticos sobre a ciência e a tecnologia, Florianópolis, Santa Catarina, Brasil.

Franco-Avellaneda, M. (2013b). Ensamblar museus de ciências e tecnologias: compreensões educativas a partir de três estudos de caso (Tesis de Doctorado, Universidade Federal de Santa Catarina, Florianópolis, Santa Catarina). Repositório Institucional da UFSC. https://repositorio.ufsc.br/xmlui/handle/123456789/122939

Franco-Avellaneda, M. (2013c). Museos, artefactos y sociedad: ¿cómo se configura su dimensión educativa?. Universitas Humanística, 1(76), 97-123. https://revistas.javeriana. edu.co/index.php/univhumanistica/article/view/3103

Franco-Avellaneda, M. (2016). Transferencia e intercambio: cuando el río suena... reflexiones para pensar el rumbo de la política de apropiación del conocimiento en Colombia. Trilogía: Ciencia, Tecnología y Sociedad, 8(15), 69-79. https://dialnet.unirioja. es/servlet/articulo? codigo $=5676640$

Franco-Avellaneda, M., \& Altafulla, D. (2007). Una experiencia de educación en ciencia y tecnología en escenarios no formales: una reflexión de contexto. Revista Internacional Magisterio, 1(27), 78-80.

Franco-Avellaneda, M., \& Arboleda, T. (2014). Apropiación Social de la Ciencia, Tecnología e Innovación para el Desarrollo Humano. Escuela Virtual PNUD-Colciencias/ Diplomado ASCTI. 
Franco-Avellaneda, M., \& Pérez-bustos, T. (28-30 de maio, 2008). Aportes para la consolidación de una propuesta de educación no formal en Ciencia y Tecnologia: uma mirada desde a pedagogía crítica y la reflexión CTS. VII Jornadas Latino-Americanas de Estudos Sociais das Ciencias e das Tecnologias, Rio de Janeiro, Rio de Janeiro.

Franco-Avellaneda, M., \& Pérez-Bustos, T. (2010). Tensiones y convergencias entorno a una apuesta por la pluralidad de la Apropiacion Social de la Ciencia y la Tecnología en Colombia. En T. Pérez-Bustos \& M. Tafur (Eds.), Deslocalizando la Apropiación Social de la Ciencia y la Tecnología en Colombia (pp. 9-23). Maloka.

Franco-Avellaneda, M., \& Von-Linsingen, I. (2011). Popularizaciones de la ciencia y la tecnología en América Latina: Mirando la política científica en clave educativa. Revista Mexicana de investigación educativa, 16(51), 1253-1272.

Freire, P. (1977). Extensão ou comunicação? (3a ed.). Paz e Terra.

Freire, P. (1979). Conscientização: teoria e prática da libertação: uma introdução ao pensamento de Paulo Freire. Cortez \& Moraes.

Freire, P. (2005). Pedagogia del oprimido. Siglo XXI editores.

Freire, P. (2011). Ação cultural para a libertade e outros escritos (14 ${ }^{\mathrm{a}} \mathrm{ed}$.). Paz e Terra.

Honey, M. A., Pearson, G., \& Schweingruber, H. (2014). STEM Integration in K-12 Education: Status, Prospects, and an Agenda for Research. National Academies Press. https://doi.org/10.17226/18612

Krug, D., \& Shaw, A. (2016). Reconceptualizing ST ${ }^{\oplus} \mathrm{E}(\mathrm{A}) \mathrm{M}(\mathrm{S})$ Education for Teacher Education. Canadian Journal of Science, Mathematics and Technology Education, 16(2), 183-200. https://doi.org/10.1080/14926156.2016.1166295

Latour, B. (1987). Science in Action, How to follow Scientist and Engineers through Society. Harvard University Press.

Latour, B. (2020). Imaginer les gestes-barrières contre le retour à la production d'avantcrise. AOC.

Martín-Barbero, J. (2005). La lectura de la encuesta. La percepción que tienen los colombianos sobre la ciencia y la tecnología. En J. Aguirre (Ed.), La percepción que tienen los colombianos sobre la ciencia y la tecnología (pp. 41-47). Colciencias.

Menezes, L. C. (1980). Novo (?) Método (?) Para ensinar (?) Física (?). Revista brasileira de ensino de física, 2(2), 89-97.

Miller, K. (2006). Canibalismo y modernidad: la historia como plato principal. Revista Iberoamericana, 72(215-216), 515-529. https://doi.org/10.5195/reviberoamer.2006.95

Pérez-Bustos, T., \& Franco-Avellaneda, M. (2005). Sobre la educación no formal, el universo tecnológico y el goce. Revista Pedagogía y Saberes, 1(23), 103-110. https://doi. org/10.17227/01212494.23pys 103.110 
Porras, Y. (2021). La educación en ciencias en un escenario de pandemia. TecnéEpisteme-Didaxis, (49), 7-15. https://revistas.pedagogica.edu.co/index.php/TED/ article/view/13151

Ramos, C., Pérez-Bustos, T., Franco-Avellaneda, M., Corrales, D., \& Aguilera, J. (2007). Una experiencia de diálogo entre la educación formal y la no formal. Nodos y nudos, 3(22), 69-80. https://doi.org/10.17227/01224328.1308

Resnick, M. (2004). Edutainment? No thanks. I prefer playful learning. MIT.

Rutherford, J. (1997). Ciencia: conocimiento para todos. Oxford University Press.

Sarlo, B. (2001). Escenas de la vida posmoderna. Editorial Ariel.

Thomas, H. (2008). Estructuras cerradas versus procesos dinámicos: trayectorias y estilos de innovación y cambio tecnológico. En H. Thomas \& A. Buch (Eds.), Actos, actores y artefactos: Sociología de la tecnología (pp. 217-262). Universidad Nacional de Quilmes.

Thomas, H. (2009). Sistemas Tecnológicos Sociales y Ciudadanía Socio-Técnica. Innovación, Desarrollo, Democracia. En T. M. Fernando \& G. Gustavo (Eds.), Culturas Científicas y Alternativas Tecnológicas. Io Encuentro Internacional (pp. 65-86). Ministerio de Ciencia, Tecnología e Innovación Productiva de Argentina.

Toma, R. B., \& García-Carmona, A. (2021). «De STEM nos gusta todo menos STEM». Análisis crítico de una tendencia educativa de moda. Enseñanza de las ciencias: revista de investigación y experiencias didácticas, 39(1), 65-80. https://doi.org/10.5565/REV/ ENSCIENCIAS.3093

${ }^{0}$ Manuel Franco-Avellaneda Investigador independiente mfrancoavellaneda@gmail.com

Diego Corrales-Caro Investigador en estudios críticos dacorralesc@gmail.com

Editora Responsable

Stefannie Ibraim

Manifesto de Atención a las Buenas Prácticas Científicas y de ausencia de conflicto de interés

Los autores declaran haber tenido cuidados éticos a lo largo del desarrollo de la investigación y no tener conflicto de interés o relaciones peronsales que puedan haber influenciado el trabajo que se relata en el texto. 